\title{
Formação por ciclos
}

\section{Formation by cycles}

\author{
Lidia Nedbajluk
}

RESUMO

Artigo desenvolvido a partir dos estudos de Mestrado na Universidade Federal do Paraná, na linha de pesquisa Currículo, Conhecimento e Saberes nas Práticas Escolares, investigando a Formação por Ciclos. Analisa a diversidade de termos utilizados como complemento ao termo ciclos no ensino fundamental (Ciclos de Aprendizagem; Escola em Ciclos; Ensino em Ciclos; Ciclos de Desenvolvimento; Ciclos de Formação; Ciclo de Estudos) e esclarece a inadequação do uso dos mesmos indistintamente. Considerando os fundamentos epistemológicos e eixos estruturadores do Currículo Escolar, faz considerações sobre promoção automática e progressão continuada e suas relações com o Ensino por Ciclos.

Palavras-chave: Ciclo; progressão continuada; promoção automática; eixos estruturadores.

\begin{abstract}
This article was developed having as source the Mastercourse studies at Universidade Federal do Paraná, based on Curriculum research, Knowledge and Acquaintance on School Practices, tracing Formation by Cycles. It analyses the diversity of terms used as complement to the term "cycles" at elementary school. (Learning cycles, School by means of cycles, Teaching by means of cycles, Development cycles, Formation cycles; Cycles of Studies) and explains the inadequacy of its use indistinctly. Considering the epistemological basis and supporting axes of School Curriculum, it ponders the automatic promotion and continued progression and its links with Teaching by means of cycles.
\end{abstract}

Key-words: Cycle; continued progression; automatic promotion; supporting axes.

\footnotetext{
* Mestre em Educação pela UFPR.
} 


\section{Introdução}

Tem-se observado nos meios educacionais, cada vez mais freqüentemente, a partir da década de 80, a implantação dos modelos de organização denominados de Ensino em Ciclos. A expansão de tal modelo se observa principalmente nas redes públicas de ensino. Essa modalidade vem sendo implantada como medidas de governos, sob a justificativa política ${ }^{1}$ da universalização do Ensino Fundamental mediante a eliminação da multirepetência e do conseqüente congestionamento do sistema.

Do ponto de vista pedagógico, tal modo de organização do ensino tem sido defendido sob o argumento da melhor possibilidade de organização do tempo e espaço escolares, do respeito aos ritmos e dos processos de aprendizagens dos alunos, da eliminação da cultura da repetência instalada na escola e da preservação da auto-estima dos alunos.

Ao lado da crescente adoção desse modo de organização do ensino, observa-se uma confusa variedade de terminologias utilizadas, acompanhando ou não o termo ciclo (Ciclos de Aprendizagem; Escola em Ciclos; Ensino em Ciclos; Ciclos de Desenvolvimento; Ciclos de Formação; Ciclo de Estudos); por outro lado, na análise de documentos oficiais que tratam da divulgação ou orientação quanto a essa forma de organização do ensino, percebe-se um elemento constante: associa-se aos ciclos a eliminação, total ou parcial, da figura da reprovação (ou retenção do aluno) na mesma etapa/ série.

Esse modelo de organização tem sido referendado e estimulado pelas políticas de governos estaduais, municipais e também pelo governo federal, mediante a Lei de Diretrizes e Bases da Educação Nacional (LDB), n. ${ }^{\circ}$ 9.394/96 (BRAsIL, 1996), e pelos Parâmetros Curriculares Nacionais para o Ensino Fundamental (PCNs.) (BRASIL, 1997). É notório que o estímulo não recai somente no modo de organizar o ensino no que tange aos aspectos pedagógicos relacionados à observância das fases do desenvolvimento humano, mas recai na eliminação da repetência, sugerida, inclusive, para os modelos de organização do ensino em série, conforme se pode ler na LDB, no seu artigo 32 (BRASIL, 1996).

${ }^{1}$ Política entendida como processos adotados pelos governos para obter determinados fins (RIBEIRO, 1986, p.16) 
Ao mesmo passo em que as políticas de governo incentivam a organização em ciclos, é facilmente encontrado material que demonstra a insatisfação dos professores com tal modelo. De outro lado, há as escolas privadas, cujo contingente de alunos é, na sua maioria, composto por alunos de classes com poder aquisitivo mais elevado e cujas expectativas de inserção no mundo do trabalho são, em geral, a manutenção ou inserção em patamares superiores do ponto de vista da competitividade e remuneração - tais escolas têm sido cautelosas em implantar o referido modelo de ensino, não se encontrando iniciativas significativas, em termos numéricos.

Completando o quadro, ainda se pode constatar, tanto em documentos escritos quanto em conversas com professores, que não há muito consenso sobre quais são os ciclos, qual sua duração, quais procedimentos de ordem didático-pedagógica são inerentes a esse modelo e qual o eixo estruturador desse modo de organização do ensino. $\mathrm{O}$ consenso resume-se a dois aspectos: a idade biológica como referência para organizar os alunos e a inexistência da repetência em todos os estágios/etapas, ou em alguns deles.

Os aspectos acima abordados circunscrevem um quadro instigante, o que nos levou a realizar estudos que resultaram na dissertação de mestrado. ${ }^{2}$ A abordagem feita no estudo não teve a preocupação em identificar qual é a melhor forma de organizar o ensino formal, do ponto de vista de seus resultados. Algumas pesquisas sobre o assunto têm se ocupado desse aspecto a partir de pesquisas de campo e avaliações dos resultados por meio de dados estatisticamente tratados. O presente artigo faz um recorte dos aspectos estudados na dissertação: a diversidade de termos utilizados para complementar a palavra ciclo, uma vez que os mesmos são usados indistintamente e considerações sobre Promoção Automática e Progressão Continuada.

A partir da análise da etimologia dos termos utilizados atualmente, ${ }^{3}$ propomos, por meio de inferências e de análise documental e revisão biblio-

${ }^{2}$ Nedbajlu. Formação por Ciclos: Políticas e Fundamentos, dissertação de Mestrado em Educação da Universidade Federal do Paraná: estudo realizado a partir da análise documental de três propostas pedagógicas referentes a três sistemas de ensino: a Escola organizada em ciclos do Município de São Paulo, implantada desde 1984; a Escola Cidadã de Porto Alegre, implantada em 1995 e a Escola Sagarana de Minas Gerais, implantada em 1998.

${ }_{3}^{3}$ Ciclos de Aprendizagem; Escola em Ciclos; Ensino em Ciclos; Ciclos de Desenvolvimento; Ciclos de Formação; Ciclo de Estudos. 
gráfica, alguma elucidação sobre as diversas terminologias utilizadas e demonstramos que não é adequado usar termos distintos (ciclos de aprendizagem, escola em ciclos, ensino em ciclos, ciclos de desenvolvimento) como se contivessem o mesmo significado.

Ao pesquisar o termo ciclo, encontramos sua origem no grego kyklos, significando série de fenômenos que se sucedem numa ordem determinada. Em termos da Biologia, refere-se ao ritmo de sucessão ou repetição de um fenômeno. Laeng (1971) afirma: nos usos biológico e psicológico tem sido ampliado para referir-se a qualquer fase concluída (ao menos em sentido relativo) de um processo de desenvolvimento. Neste sentido, o vocábulo tem sido usado na reorganização dos chamados "cursos" inferiores e superiores da escola elementar, para relacionar a reconstrução intencional com os ritmos naturais do desenvolvimento infantil, para além do rígido limite convencional das classes estabelecidas segundo o ano solar. A unidade do ciclo é, sobretudo, didática: relaciona-se o primeiro nas aprendizagens mais globais e, durante o segundo, nas aprendizagens mais complexas a partir das primeiras, respeitando a unidade e superando a dispersão fragmentária das relações naturais.

\section{Os ciclos na educação são uma inovação?}

$\mathrm{Na}$ Educação, quando existe um conjunto de práticas que um grupo social promove para que seus membros assimilem a experiência acumulada, convertendo-se em membros ativos do mesmo, sempre há ensino. Seja pela orientação intencional, explícita e sistemática, seja pelo exemplo espontâneo e imitação, as aprendizagens envolvem ensino. Tais processos de ensino, espontâneos e assistemáticos ou intencionais e sistemáticos, obedeciam nos primórdios aos ciclos de desenvolvimento, sobretudo biológico e, naturalmente, se relacionavam com a cultura do grupo. Quando o bebê da família primitiva ainda não se locomovia por sua própria conta, não se alimentava, não se abrigava das intempéries por sua conta, tais coisas (neste ciclo de desenvolvimento do indivíduo) eram providas pelo adulto até que atingisse o estágio de poder fazer sozinho aquilo que via os membros mais experientes fazerem, alcançando assim um outro ciclo: sai da dependência total do mais experiente e passa a colaborar na sobrevivência de si e do seu grupo social. 
Acompanhando as rotinas diárias, pela imitação (e o adulto então praticava ensino, ainda que não se desse conta disso) aprendia a fazer as coisas que seu estado de desenvolvimento físico permitisse e suas aprendizagens cognitivas viabilizassem. Assim se dava com o manejo das armas de caça e defesa, com a confecção de abrigos e roupas, etc.

É possível afirmar, por esse raciocínio, que já nos primórdios da civilização a aprendizagem se estruturava a partir de ciclos de desenvolvimento. $\mathrm{O}$ eixo estruturador se localizava no que havia para ser aprendido e no desenvolvimento biopsíquico. Entrava no ciclo seguinte quem tivesse dado conta de aprender a defender-se, abrigar-se, obter sua comida, impor respeito perante o grupo, etc. Os rituais de iniciação adotados em algumas sociedades podem ser interpretados como passagem de um ciclo a outro.

Nas sociedades mais desenvolvidas do ponto de vista das ciências, técnicas e tecnologias passou-se demandar aprendizagens cada vez mais complexas e diferenciadas. O ensino, por decorrência, passou por modificações de modo a adequar-se às demandas de cada sociedade e época. Para exemplificar, na antiga Grécia o eixo organizador do conteúdo era a própria cultura, no sentido sociológico. Enquanto os versos de Homero exaltavam as qualidades do homem nobre, Hesíodo tratava do apreço pelo trabalho (WERNER, 1979, p. 78). Ensinava-se e aprendia-se aquilo que fazia parte do cotidiano, no trabalho, nas artes. O que havia para ser ensinado e aprendido dependia da classe social a que se pertencia. O tempo para aprender era o tempo necessário para cada aprendiz, determinado biológica e culturalmente: as idades, os ritos de iniciação, as classes sociais. A reprovação como elemento regulador do ensino ainda não havia entrado em cena.

Como em toda a sociedade, os valores sociais e econômicos vigentes determinavam os fins, objetos, meios e os destinatários da educação, que se realizava na praça pública, nos lares, nas oficinas, nos campos e em alguns casos em escolas. O Estado passa a assumir importante papel na educação pública dos jovens, por meio de concursos ginásticos e musicais, onde se exaltavam os deuses e valores desejáveis para a época (WERNER, 1979, p. 131).

No conteúdo dos poemas da época percebem-se as características do homem aristocrático da Grécia do século V: vida sedentária, posse de bens materiais e tradição transmitida de pai para filhos, aos quais era necessário prover uma educação diferenciada (WERNER, 1979, p. 40). Educação, enquanto refinamento, conhecimento das artes e ciências era destinada apenas aos cidadãos. E cidadão na Grécia antiga era o aristocrata, grego de origem e detentor de posses. Para estes havia escolas para aprender a leitu- 
ra e escrita e também ginástica e música. Aos demais, o que havia para ser ensinado e aprendido era o ofício, o modo de, por meio do trabalho, prover sua existência e a do seu senhor (WERnER, 1979, p. 107). Com o surgimento do ensino formal e em função do volume de conhecimentos a ser aprendido, que em muito supera a capacidade média de aprendê-lo durante uma vida, impõe-se a necessidade de selecioná-lo e estruturá-lo de forma a possibilitar sua apreensão.

$\mathrm{Na}$ era moderna, com o grande desenvolvimento das ciências e a industrialização, passou-se a organizar o ensino segundo a lógica das matérias científicas e de acordo com os conceitos de produção em série, onde a eficiência era buscada e, portanto, voltada para resultados, inclusive no ensino.

O conhecimento escolar passa a ser organizado a partir das disciplinas científicas, em função da crescente especialização das áreas do conhecimento. Conteúdos e métodos seguem um padrão único para todos os alunos de uma turma. A organização e a distribuição dos conteúdos, em espaços e tempos, fazem coincidir um ano civil com um ano letivo e com um conjunto de conteúdos previstos. Cada período letivo constitui-se em sub-segmento fechado em torno de tempos fixos, denominados série. $\mathrm{O}$ processo do ensino passa a ser orientado por resultados esperados. A flexibilização, isto é, a maneira de resolver aqueles casos que fugissem do padrão esperado, recaía na repetição do percurso (ou, nos termos de hoje: a reprovação). É o denominado ensino seriado.

Tal forma de organização perdurou por muito tempo e várias gerações se educaram sob esse sistema, a ponto de perder-se de vista que o modelo de ensino sistemático e formal não foi sempre assim.

Mais recentemente é que se voltou a pensar o ensino organizado em ciclos. Em função do congestionamento de fluxo causado pelo número exagerado de repetências no Brasil, nos meados dos anos 20 e 50 do século passado, medidas de ordem política provocaram propostas de ordem pedagógica, a implantação dos (então) denominados ciclos. O aluno cumpriria um determinado percurso, isto é, aquele mesmo conteúdo, organizado a partir da estrutura das matérias ou disciplinas, repartidas em seções anuais, seria trabalhado com os alunos e estes teriam promoção automática garantida.

Os resultados, se negativos, seriam punidos não mais pela reprovação na escola e sim pelo mercado de trabalho. À população seria dada a "chance" de aprender mediante a garantia de acesso à escola. E para isso, se argumentou na época (década de 20), os menos capazes não poderiam se cons- 
tituir em obstáculo ao andamento do fluxo de alunos por causa das suas reprovações. Para ilustrar citamos:

... em 1921, na Conferência Interestadual de Ensino Primário, (...) o Diretor Geral do Ensino recomendava a "promoção em massa". Em 1918 Sampaio Dória aconselhava expressamente o seguinte: "promover do primeiro para o segundo período todos os alunos que tivessem tido o benefício de um ano escolar, só podendo os atrasados repetir o ano, se não houver candidatos aos lugares que ficariam atrasados". Semelhante medida equivale a não permitir que se negue a matrícula aos novos candidatos, só porque vadios ou anormais teriam de repetir o ano (ALMEIDA, 1957).

A nosso ver, propunham-se na época os ciclos como uma rodada de estudos. E a promoção se daria pela passagem por esses estudos.

Recomendava-se, na época, agrupar os alunos por idade cronológica, mas o eixo estruturador recaía nas matérias (ou disciplinas). A proximidade etária se instalaria naturalmente, à medida que se impunha uma idade mínima para o ingresso no processo de escolarização e, não havendo reprovações, a tendência era manter-se o aluno no grupo de sua faixa etária.

A lógica pela qual todo o ensino seria organizado, a começar pelo conteúdo e as disciplinas, estaria orientada pela lógica e estrutura das ciências que lhes deram origem. A organização do ensino resultava da transposição didática dos conhecimentos científicos a partir dos seus aspectos epistemológicos. Tais conteúdos continuariam fixos para cada ano de estudos. Os resultados é que seriam flexibilizados (ao contrário das séries, onde se exigiam determinados resultados para promoção, independente da idade ou do número de vezes que se cursasse a mesma série).

Concluímos então que, apesar de na época tal organização do ensino ser conhecida apenas como ciclo, é possível (para elucidar as diversas terminologias utilizadas hoje) propor que o ciclo assim organizado consistia num ciclo de estudos, pois a promoção de um grau a outro dar-se-ia independentemente das aprendizagens conquistadas, ou seja, automaticamente.

Considerando os exemplos dados, é nossa conclusão que o uso do termo ciclo para referir-se ao modo como o ensino se organiza não é suficiente e requer um complemento. $\mathrm{O}$ que definiria e distinguiria esse complemento? 


\section{Os eixos estruturadores do currículo}

Se tomarmos como pressuposto que, ao prover Educação, cada sociedade o faz com o propósito de "preparação das novas gerações para sua participação no mundo do trabalho e na vida pública" (SACRISTÁN, 1998, p. 13) e que isso "requer a intervenção de instâncias específicas como a escola" (idem), onde é provido o ensino, é razoável concluir que o ensino é que é organizado em ciclos. Resta ainda, para delimitar melhor o que complementaria o termo ciclo, definir o que distingue os diversos complementos (de aprendizagem, de formação humana, de estudos, de desenvolvimento) atualmente utilizados (indistintamente) nos documentos oficiais (projetos pedagógicos) e nos textos de fundamentação teórica.

Em nossa revisão bibliográfica encontramos em Saviani (1998) que diferentes formas de organizar o ensino se orientam por diferentes eixos estruturadores do currículo.

Estudiosos do currículo dão conta das diferentes formas de concebêlo: os que enfatizam "resultados que se espera ver exibidos como conseqüência da aprendizagem"; currículos que enfatizam o "conjunto de experiências subordinadas e controladas pela escola" e os que enfatizam currículo como "princípios essenciais de uma proposta educativa" (PEDRA, 1997, p. 32). E, ainda, as decisões sobre o modo de organizar o currículo, em decorrência da organização do ensino que se deseja, têm, tradicionalmente, se orientado por três posturas básicas, de ordem epistemológica, conforme indicado por Saviani (1998) em estudo que desenvolveu sobre o papel do conteúdo na elaboração dos currículos. As ênfases, como eixos estruturadores, recaem nos aspectos: a) sociológico; b) psicológico e, c) estrutura interna dos conteúdos.

Com base nesses eixos estruturadores, nossa pesquisa nos leva a concluir que os ciclos podem referir-se a: ciclos de estudo; ciclos de aprendizagem; ciclos de formação humana ou de desenvolvimento.

Os Ciclos de Estudos têm seu eixo organizador situado preponderantemente no programa, isto é, a organização vertical do curso prevê que o aluno deve estudar determinados conteúdos que, geralmente, têm uma lógica organizacional estabelecida em função das matérias ou disciplinas (estrutura interna dos conteúdos). Por isso mesmo tendem a compor um sistema graduado, com aprofundamentos gradativos do mais simples para o mais complexo. A mobilidade entre um grau de estudos e outro está vincu- 
lada, em certa medida, porém não exclusiva nem preponderantemente, na apreensão dos conteúdos previstos no programa. É necessário que o estudante freqüente e cumpra um programa. Os resultados dos alunos poderão ser muito diversos, variando muito o grau de apreensão do programa. Neste caso, a flexibilização será definida pelos requisitos que sejam definidos para a mobilidade entre um ciclo de estudos e outro. Poderá haver certos casos em que a passagem de um ciclo de estudos para outro não exija comprovação de domínio de conteúdos do anterior. É o caso de ciclos de estudos independentes.

Os Ciclos de Aprendizagem têm seu eixo organizador situado preponderantemente em torno dos resultados esperados, isto é, nas aprendizagens obtidas. É necessário que o aluno adquira certos conhecimentos e desenvolva certas competências, estabelecidas como mínimos essenciais e, portanto, se constituem como condição ou pré-requisito para a progressão a um nível superior, a graus de aprofundamento e complexidade crescentes do conteúdo. Neste caso a flexibilização recai nos tempos despendidos pelo estudante, pois, dependendo de suas capacidades pessoais, poderá progredir de um grau para outro ao seu próprio ritmo, em tempos diferentes de seus pares. É o que ocorre com alguns programas de jovens e adultos, por exemplo, onde se exige que comprove domínio acadêmico (a partir de um programa proposto) sem necessariamente freqüentar (todas) as aulas ou cumprir um curso; enfim, sem cumprir uma mesma carga horária de estudos presenciais.

A terceira ênfase seria a psicológica, na qual pode-se citar os Ciclos de Formação Humana (ou de Desenvolvimento), tendo seu eixo estruturador orientado nas fases de desenvolvimento humano. A ênfase recai no aluno, suas características biopsicossociais. Neste caso, os programas subordinam-se (ou deveriam) às características das fases de desenvolvimento, que por sua vez, mantêm certa relação ${ }^{4}$ com as faixas etárias e características culturais. A flexibilização recai no programa e nos resultados, exigindo-se grande capacidade de adequação dos primeiros (programas) aos grupos de alunos de modo que, ao mesmo tempo em que se respeitem suas características e conquistas cognitivas, promova novas conquistas pela via das transmissões sociais (o ensino escolar neste caso) a partir dos conceitos já desenvolvidos. Admitem-se diferentes resultados no final do processo.

${ }^{4}$ Relação relativa, não exclusiva nem definitiva. 
Neste caso, a capacidade de planejamento e a efetivação da ação pedagógica, atendendo às peculiaridades de cada aluno, resultariam como conseqüência natural que a progressão se dê de forma continuada, não necessariamente em bloco de alunos, não necessariamente nos mesmos tempos, tampouco com os mesmos resultados. Evidencia-se aqui a importância de entender e colocar a serviço do ensino formal mecanismos eficientes de avaliação processual no seu sentido mais amplo e profundo: admitindo-se que em determinada fase do desenvolvimento humano o aluno é capaz de dominar certos conhecimentos e competências, é necessário que o desenvolvimento de tais competências seja garantido mediante intervenções pedagógicas adequadas, o que demanda identificar (diagnosticar) em cada aluno o que já sabe e como desenvolve suas aprendizagens.

Esse diagnóstico será o ponto de partida para a organização da ação pedagógica mediadora, tendo em vista o que se propõe que deva (ou precise) saber. Convém rememorar que, de acordo com as teorias ${ }^{5}$ que são tomadas para dar sustentação a esse tipo de organização, as aprendizagens (escolares) são possíveis em determinadas fases, porém não ocorrem espontaneamente. Isso remete à maior responsabilidade sobre o modelo e eficiência da intervenção pedagógica, que requer condições de ordem teórico-prática: desde a capacitação dos profissionais do ensino até as reais condições de articulação de recursos físicos e humanos que viabilizem trabalhar com a diversidade, afastando-se do tratamento de massa ou de blocos de alunos.

\section{As demandas do ensino em Ciclos de Desenvolvimento (ou de Formação)}

O desenvolvimento biopsicossocial é extremamente particularizado, pois as aprendizagens não se dão ao mesmo tempo e do mesmo modo para todos. A idade cronológica é apenas um dos fatores a serem levados em conta. As teorias de Piaget e Vygotsky (palangana, 1994), além de outras contribuições relevantes no assunto, mapearam as principais conquistas

${ }^{5}$ Teorias de Piaget e Vygotsky (Teberosky, 1997), entre outros. 
cognitivas e indicaram que elas se dão no sujeito, mediante processos internos de construção e mediadas pelas interações sociais. Porém, os autores alertam que tais progressos não são iguais em todas as pessoas: estão em grande parte sujeitos às condições externas, ao meio, ao tipo de experiências vividas, às contribuições sociais e também às condições internas de cada pessoa, muito particularizadas, às estruturas mentais que se estabeleceram.

A conjugação desses dois fatores (aí estão incluídos aspectos da afetividade) produz resultados distintos nos sujeitos que, apesar de receberem estímulos iguais, não há garantia, aliás há certeza que chegarão a resultados diversificados. Isso traduzido para a sala de aula significa que se o desenvolvimento do currículo for idêntico para todos os alunos de um determinado Ciclo de Desenvolvimento (ou de Formação), os resultados mínimos esperados, ou seja, as aprendizagens essenciais, poderão não ser garantidas a toda a população de crianças e adolescentes que freqüentam o Ensino Fundamental, o que caracterizará um Ciclo de Estudos com promoção automática.

É necessário que a escola esteja capacitada para oferecer diferentes tipos de intervenção, atendendo às particularidades que se apresentam (e, muitas vezes, dificuldades de aprendizagem - elas são reais) de forma diversificada do ponto de vista da metodologia, da carga horária, dos atendimentos especializados, se necessários, e imediatamente quando necessários, pois é inerente à proposta a não descontinuidade do ponto de vista do desenvolvimento de cada aluno. A continuidade não se dá apenas na construção do conhecimento pelo sujeito. No ensino sistemático, a continuidade e a apropriabilidade das intervenções pedagógicas devem aproximar-se das características individuais do aluno de modo que promovam acesso a novos patamares do conhecimento. Do contrário, é engodo.

É neste contexto que a progressão continuada se afasta da promoção automática, caracterizada por todos os malefícios que caracterizam esta última (tão negada pelos órgãos oficiais responsáveis pelas políticas de educação): quando, de fato, no dia-a-dia escolar forem colocados imediatamente recursos pedagógicos, que muito freqüentemente requerem recursos financeiros, para atender de modo diverso e diversificado a multiplicidade de situações em que os alunos se encontrem.

Promoção automática, por definição, refere-se à ação de elevar de posto ou de emprego, graduação ou categoria, de forma automática, sem o controle da vontade própria ou de alguém. Por outro lado, progressão continuada refere-se a desenvolvimento, continuação ou acrescentamento de 
uma ação ou estado, aumento de significado e alcance da experiência humana de forma ininterrupta.

O que se quer é garantir a apreensão de conhecimentos que são, no Ensino Fundamental, por definição fundamentais para a vida na sociedade atual. Sem tais conhecimentos estará sendo produzida uma legião de excluídos da mesma forma que o são os reprovados (e que não são exclusividade do ensino organizado em séries: os sistemas seriados poderão admitir progressão continuada, assim como há ciclos implantados nos sistemas de ensino formal, que admitem a reprovação).

Isso nos leva a concluir que um ensino organizado por Ciclos de Formação, em função de ter seu eixo estruturador alicerçado nas fases de desenvolvimento cognitivo, que por sua vez se referencia no desenvolvimento biopsicológico, deverá ter um desenho curricular estruturado a partir das ditas fases e considerando as particularidades de cada aluno, levando em consideração ainda os aspectos sociológicos envolvidos, além de selecionar os conteúdos e metodologias adequados do ponto de vista da psicologia e da sociologia, coerentes do ponto de vista epistemológico de cada disciplina, tendo assim uma Proposta Pedagógica que sirva como diretriz curricular para os alunos nos diferentes ciclos.

Ainda assim, os resultados serão diferentes. Haverá alunos em estágios diferentes, isto está previsto pela psicologia, e nesse caso é que o Ciclo de Formação só o será se puder prestar atendimento pedagógico de forma diferenciada, em termos de flexibilidade, agilidade e apropriabilidade metodológica aos estágios e conquistas, em termos de desenvolvimento de cada aluno.

A heterogeneidade é uma das características da organização do ensino em Ciclos de Formação, pois os seres humanos são heterogêneos por natureza. No entanto, na organização de atividades de ensino, a heterogeneidade nem sempre será aliada do aluno ou do professor. A diversidade presente nos grupos de alunos, ao contrário, sugere que são necessárias a diversidade e dinamicidade nas formas de organização. Ora, será recomendável, do ponto de vista pedagógico, que diferentes níveis de domínio de conteúdo e desenvolvimento de competências trabalhem juntos. Em outros momentos será mais recomendável trabalhar com os que têm semelhantes domínios, seja para promover superação das dificuldades comuns, seja para não impor um ritmo mais lento nos avanços de um grupo de alunos em detrimento do ritmo da média.

O princípio orientador do ensino organizado em Ciclos de Formação é a fase de desenvolvimento do aluno, não necessariamente sua faixa etária. 
A partir daí, o trabalho pedagógico deve ser no sentido de provê-lo com conteúdos que, considerando as estruturas mentais desenvolvidas, viabilizem a apreensão de conhecimentos e o desenvolvimento de competências relevantes para a sua época e seu meio social.

Considere-se também que a apreensão de certos conteúdos escolares, em muitos casos, está subordinada à construção de conceitos anteriormente desenvolvidos (o conhecimento científico obedece a determinadas lógicas, sem as quais não haverá apreensão nem compreensão, talvez memorização temporária). Admitindo-se que numa mesma sala de aula, cujo agrupamento foi feito pela idade cronológica (à qual correspondem certas capacidades mentais, mas não necessariamente apreensão do conhecimento escolar previsto), como insistir em ensinar a todos a mesma coisa, do mesmo modo, ao mesmo tempo?

Deriva disso que a escola que pretenda organizar o ensino por Ciclos de Formação precisa organizar-se (e ter condições estruturais para isso) de forma a poder identificar no aluno o estágio (de desenvolvimento cognitivo e competências acadêmicas) em que ele está e trabalhar a partir daí. Significa, tendo uma referência curricular, a escola adaptar-se aos diferentes alunos que nela estudam, ao invés do contrário, isto é, o aluno adaptar-se à escola. No entanto, não fica dispensada a necessidade de garantir que, ao final do processo, ele tenha apreendido os conhecimentos mínimos (ou fundamentais) previstos, pois assume a escola que, em determinada idade biológica, o sujeito aprendiz está, via de regra, em condições psicológicas de apreender determinados conteúdos científicos necessários do ponto de vista sociológico.

É necessário não perder de vista que se está aqui dando ênfase ao Ensino Fundamental, de direito e obrigatório a toda a população. Isso exige ainda algumas considerações: admitindo-se que possa haver discussão quanto à relevância de alguns conteúdos escolares ou competências desenvolvidas por meio deles, há, no entanto, aqueles que não admitem discussão quanto a sua importância na sociedade letrada: ler, escrever e contar, por exemplo, são algumas dessas competências. É notório, já dissemos antes, pois têm sido freqüentes as publicações na imprensa comum de relatos de alunos que concluem o Ensino Fundamental sem ter adquirido, de forma elementar, tais competências. Certamente não se está creditando tais resultados negativos ao ensino organizado em ciclos. Porém, como a flexibilização desta forma de organização recai no conteúdo, há maiores possibilidades de o aluno concluir o Ensino Fundamental sem domínio das competências mínimas, que se constituem no acesso ao conhecimento necessário para a 
compreensão e transformação da realidade, isto é, da cidadania e superação das desigualdades sociais, justamente a preocupação evocada nas justificativas à introdução ao ensino organizado em ciclos de formação. Ao contrário, poderá ao longo do tempo transformar-se no ensino que produz segregação e seletividade, pois, produzindo alunos egressos de um sistema de escolarização que não garante as aprendizagens relevantes e essenciais para a sociedade em que estão inseridos, provocam diferenças muito acentuadas nos níveis de competência desenvolvidos. Tais diferenças se constituem na divisão de saberes e a divisão dos saberes pode se transformar na divisão do trabalho, ou nas possibilidades de acesso a ele, resultando na segregação social.

Assim, para finalizar, fazemos ainda uma última consideração: a necessidade de no modelo de organização de ensino por Ciclos de Formação, além de um aparato que processualmente garanta a intervenção pedagógica que o aluno necessite para superar as possíveis (e sempre presentes) dificuldades (mais efêmeras ou mais perenes), avaliar de forma institucional os resultados obtidos. Evidentemente que esse é um requisito não exclusivo da organização do ensino em Ciclos de Formação com progressão continuada. Avaliar resultados é requisito de todo e qualquer modelo que se compromete com a qualidade. No entanto, pela característica de promoção continuada, esse cuidado se torna mais relevante, pois o que resta ao final de todas as tentativas de diferenciar, no campo teórico, os termos promoção automática e progressão continuada, pode resultar bastante frágil na prática.

É nesse sentido que se faz necessário um tipo de avaliação institucional que vise identificar (e intervir, se necessário) se o aluno, ao término do processo de Ensino Fundamental, aprendeu o fundamental. No sistema seriado, as notas dos alunos - que, apesar das distorções e exageros, podem não revelar a realidade - ainda assim dão uma relativa dimensão do problema das não aprendizagens, tornando-se denúncia. No modelo ciclado, é muito comum, sob o signo de avaliação processual (mal compreendido e mal efetivado), instalar-se outra forma de distorção, igualmente prejudicial: a falta de denúncia (mecanismos de identificação do grau de apropriação dos conhecimentos) das mesmas não aprendizagens, não resolvidas tal como no ensino seriado. Porém, sem serem denunciados anualmente (como o são no ensino seriado por meio dos índices de reprovação), acumulam-se, produzindo os "filhos dos ciclos" que, acessando a escola mas não acessando o conhecimento necessário, têm seu destino atrelado à cega seleção do mercado de trabalho, um dos elementos reguladores da organização social, 
como resultado de uma invisível conversão do Ensino organizado em Ciclos de Formação em Ciclos de Estudos com promoção automática.

\section{REFERÊNCIAS}

ALMEIDA JÚNIOR. A Repetência ou promoção automática? Revista de Estudos Pedagógicos, Rio de Janeiro, v. 27, n. 65, jan./mar. 1957.

BRASIL. Lei de diretrizes e bases da educação nacional (LDB), nº 9.394, de 23 de dezembro de 1996. Brasília: Diário Oficial da União, 1996.

. Secretaria de Educação Fundamental. Parâmetros curriculares nacionais (PCNs.). Brasília: MEC/SEF, v. 1, 1997.

COLL, C. Psicologia e currículo: uma aproximação psicopedagógica à elaboração do currículo escolar. Buenos Aires: Paidós, 1987.

FORQUIN, J. C. Escola e cultura: as bases sociais e epistemológicas do conhecimento escolar. Porto Alegre: Artes Médicas, 1993.

LAENG, M. Vocabulário de Pedagogia. Barcelona: Herder, 1971.

PALANGANA, I. C. Desenvolvimento e aprendizagem em Piaget e Vygotsky. São Paulo: Plexus Ltda., 1994.

PEDRA, J. A. Currículo, conhecimento e suas representações. Campinas: Papirus, 1997.

PIAGET, J. A psicologia da criança. Trad. Octavio Mendes Cajado. 16. ed. Rio de Janeiro: Bertrand Brasil, 1999.

RIBEIRO, J. U. Política. Rio de Janeiro: Nova Fronteira, 1986.

SACRISTÁN, J. G. Compreender e transformar o ensino. 4. ed. Porto Alegre: Artmed, 1998.

SAVIANI, N. Saber escolar, currículo e didática. São Paulo: Autores Associados, 1998.

TEBEROSKY, A. Cem anos com Piaget. In: Substratum: temas fundamentais em psicologia e educação, Porto Alegre, v. 1, n. 1, 1997.

WERNER, J. Paidéia: A formação do homem grego. Trad. Artur M. Parreira. São Paulo: Martins Fontes, 1979.

Texto enviado em 05 fev. 2005

Texto aprovado em 18 abr. 2005 